NASA/TM-2001-211343

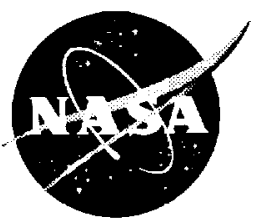

\title{
Fully Coupled Micro/Macro Deformation, Damage, and Failure Prediction for $\mathrm{SiC} / \mathrm{Ti}-15-3$ Laminates
}

Brett A. Bednarcyk

Ohio Aerospace Institute, Brook Park, Ohio

Steven M. Arnold and Brad A. Lerch

Glenn Research Center, Cleveland, Ohio 
Since its founding, NASA has been dedicated to the advancement of aeronautics and space science. The NASA Scientific and Technical Information (STI) Program Office plays a key part in helping NASA maintain this important role.

The NASA STI Program Office is operated by Langley Research Center, the Lead Center for NASA's scientific and technical information. The NASA STI Program Office provides access to the NASA STI Database, the largest collection of aeronautical and space science STI in the world. The Program Office is also NASA's institutional mechanism for disseminating the results of its research and development activities. These results are published by NASA in the NASA STI Report Series, which includes the following report types:

- TECHNICAL PUBLICATION. Reports of completed research or a major significant phase of research that present the results of NASA programs and include extensive data or theoretical analysis. Includes compilations of significant scientific and technical data and information deemed to be of continuing reference value. NASA's counterpart of peerreviewed formal professional papers but has less stringent limitations on manuscript length and extent of graphic presentations.

- TECHNICAL MEMORANDUM. Scientific and technical findings that are preliminary or of specialized interest, e.g., quick release reports, working papers, and bibliographies that contain minimal annotation. Does not contain extensive analysis.

- CONTRACTOR REPORT. Scientific and technical findings by NASA-sponsored contractors and grantees.
- CONFERENCE PUBLICATION. Collected papers from scientific and technical conferences, symposia, seminars, or other meetings sponsored or cosponsored by NASA.

- SPECIAL PUBLICATION. Scientific, technical, or historical information from NASA programs, projects, and missions, often concerned with subjects having substantial public interest.

- TECHNICAL TRANSLATION. Englishlanguage translations of foreign scientific and technical material pertinent to NASA's mission.

Specialized services that complement the STI Program Office's diverse offerings include creating custom thesauri, building customized data bases, organizing and publishing research results ... . even providing videos.

For more information about the NASA STI Program Office, see the following:

- Access the NASA STI Program Home Page at http://www.sti.nasa.gov

- E-mail your question via the Internet to help@sti.nasa.gov

- Fax your question to the NASA Access Help Desk at 301-621-0134

- Telephone the NASA Access Help Desk at 301-621-0390

- Write to: NASA Access Help Desk NASA Center for AeroSpace Information 7121 Standard Drive Hanover, MD 21076 
NASA/TM-2001-211343

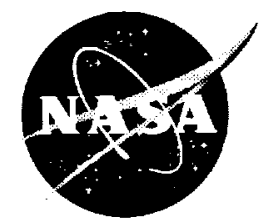

\section{Fully Coupled Micro/Macro Deformation, Damage, and Failure Prediction for $\mathrm{SiC} / \mathrm{Ti}-15-3$ Laminates}

Brett A. Bednarcyk

Ohio Aerospace Institute, Brook Park, Ohio

Steven M. Arnold and Brad A. Lerch

Glenn Research Center, Cleveland, Ohio

National Aeronautics and

Space Administration

Glenn Research Center 
Trade names or manufacturers' names are used in this report for identification only. This usage does not constitute an official endorsement, either expressed or implied, by the National Aeronautics and Space Administration.

Available from

NASA Center for Aerospace Information 7121 Standard Drive

Hanover, MD 21076
National Technical Information Service 5285 Port Royal Road Springfield, VA 22100

Available electronically at http://gltrs,grc.nasa.gov/GLTRS 


\title{
Fully Coupled Micro/Macro Deformation, Damage, AND FAILURE PREDICTION FOR SIC/TI-15-3 LAMINATES
}

\author{
Brett A. Bednarcyk \\ Ohio Aerospace Institute \\ Brook Park, Ohio 44142 \\ Email: bednaresk osicnasagor \\ Steven M. Arnold and Brad A. Lerch \\ National Aeronautics and Space Administration \\ Glenn Research Center \\ Cleveland, Ohio 44135
}

\begin{abstract}
The deformation, failure, and low cycle fatigue life of SCS-6/Ti-15-3 composites are predicted using a coupled deformation and damage approach in the context of the analytical generalized method of cells (GMC) micromechanics model. The local effects of inelastic deformation, fiber breakage, fiber-matrix interfacial debonding, and fatigue damage are included as sub-models that operate on the micro scale for the individual composite phases. For the laminate analysis, lamination theory is employed as the global or structural scale model, while GMC is embedded to operate on the meso scale to simulate the behavior of the composite material within each laminate layer. While the analysis approach is quite complex and multifaceted it is shown, through comparison with experimental data, to be quite accurate and realistic while remaining extremely efficient.
\end{abstract}

\section{INTRODUCTION}

Advanced titanium matrix composites (TMCs) continue to tantalize the aerospace research and design community. For years these materials have offered seemingly limitless potential for super lightweight components with outstanding mechanical properties. However, an array of challenges, such as manufacturability, fiber-matrix incompatibility, poor transverse properties, and environmental attack, have yet to be overcome and have, in a large part, kept TMCs in the realm of research and on the sideline in terms of design.

An additional challenge related to TMCs involves the development of accurate material and structural design and analysis tools. The titanium matrices that are mainly responsible for these composites' attractiveness for aerospace applications undergo inelastic and time/history dependent deformation - even during manufacturing. Residual stresses that arise during the cooling of the composite from the consolidation temperature, while present in all composites, have a major impact on the behavior of TMCs. Debonding at the interface of the fiber and matrix is an additional characteristic typically found in TMCs. Further confounding the situation is the fact that most of these phenomena are not directly measurable. Clearly, analysis of TMCs requires more than just simple linear elastic approaches, such as rule of mixtures equations, which have proven adequate for the ubiquitous polymer matrix composites. In order to predict the response of TMCs with any degree of accuracy, more advance and complex analysis approaches are needed that account for the characteristics of TMCs described above. 
One micro scale analysis approach that has proven to be quite accurate (in certain situations) for TMCs is that of finite element analysis (FEA). Commercial FEA software packages, which allow the incorporation of arbitrary inelastic constitutive models for the metal matrix, have been used extensively with unit cell approaches to model TMCs (Mall and Nicholas, 1998; Clyne and Withers, 1993). However, the accurate inclusion of effects such as residual stresses, fiber-matrix debonding, and fiber breakage are difficult. Further, FEA based approaches often require complex boundary conditions to be applied to the unit cell. This can make applying different types of loading combinations cumbersome. Finally, FEA unit cell approaches require a large number of elements, so if analysis of a number of fibers in a certain arrangement is desired, or if the composite being analyzed is part of a larger structural problem, the FEA problem can quickly become intractable.

The approach taken herein employs a micromechanics model known as the generalized method of cells (GMC) (Aboudi, 1991, 1995). This model is analytical in nature (as opposed to the numerical FEA) and its formulation involves application of several governing conditions in an average sense. This averaging renders the model less accurate than FEA at the micro scale due to a decoupling between normal and shear field components, but makes it many times more efficient computationally. Unlike some analytical models, GMC does provide the local fields in composite materials, allowing incorporation of arbitrary inelastic constitutive models for the composite phases as well as other micro scale effects such as fatigue damage, fiber breakage, and fiber-matrix debonding. Perhaps most importantly, GMC results in closed-form constitutive equations for the composite, which, combined with its efficiency, makes the model ideal for inclusion within larger structural analysis approaches to simulate the composite behavior at a material point.

In this investigation, many of the analysis considerations discussed above are exercised. The TMC under consideration is silicon carbide/titanium ( $\mathrm{SiC} / \mathrm{Ti}$ ). The particular fiber and matrix alloy are SCS-6 and Ti-15-3, respectively. This material system has attracted a significant amount of attention over the past decade due to its relative ease of manufacture, low cost, and attractiveness as a model material system (Arnold and Castelli, 1995) for high-temperature aerospace structural applications (e.g., in air breathing engines). GMC has been employed to simulate the tensile deformation, failure, and low cycle fatigue (LCF) life of unidirectional SCS-6/Ti-15-3, as well as SCS-6/Ti-15-3 laminates. The inelastic behavior of the Ti-15-3 has been modeled using incremental (time-independent) plasticity theory, which is relatively easy to characterize. Local (micro scale) models for longitudinal fiber breakage (Curtin, 1991), fiber-matrix debonding (Bednarcyk and Arnold, 2000a), and fatigue damage (Amold and Kruch, 1994) have been included as well. For analysis of the TMC laminate, GMC has been embedded within lamination theory, which is used to model the laminate as a structure. In these simulations, GMC operates on the meso scale, between the global scale of the laminate and the micro scale of the individual phases in the composite. The GMC analysis represents the behavior of the composite material at the integration points within each layer of the laminate. The approach is fully coupled in that the analysis on each scale affects the other scales as localization and homogenization occur repeatedly throughout the application of the simulated applied loading. Further, the fatigue damage analysis couples the micro, meso, and global scales as small amounts of damage are applied incrementally and after each applied increment, the stress in the laminate is recalculated to allow for the redistribution due to the accumulation of damage. Clearly, an equivalent analysis would be (at best) quite cumbersome using only FEA. 


\section{Micromechanics MOdel: The GeNERALIZED METHOD OF CELlS}

The micromechanics model employed to simulate the response of the $\mathrm{SiC} / \mathrm{Ti}-15-3$ composite is the generalized method of cells (GMC) developed by Aboudi $(1991,1995)$. The geometry of the doubly periodic version of GMC is shown in Fig. 1, wherein the microstructure of a periodic material is represented by a rectangular repeating unit cell consisting of an arbitrary number of rectangular subcells, each of which may be a distinct material. The method assumes a linear displacement field in each subcell and imposes continuity of traction and displacement components between subcells in an average sense (Aboudi, 1995). This procedure results in a system of linear equations,

$$
\tilde{\mathbf{A}} \varepsilon_{s}-\tilde{\mathbf{D}}\left(\varepsilon_{s}^{p}+\alpha_{s} \Delta T\right)=\mathbf{K} \overline{\boldsymbol{\varepsilon}}
$$

which are solved for the vector of all subcell strains, $\boldsymbol{\varepsilon}_{s}$, to form strain concentration equations,

$$
\boldsymbol{\varepsilon}_{s}=\mathbf{A} \bar{\varepsilon}+\mathbf{D}\left(\varepsilon_{s}^{p}+\alpha_{s} \Delta T\right)
$$

In the above equations, $\tilde{\mathbf{A}}, \tilde{\mathbf{D}}$, and $\mathbf{K}$ are matrices containing information on the repeating unit cell geometry and the properties of the constituent materials, $\bar{\varepsilon}$ is the vector of the global (unit cell) strain components, $\varepsilon_{s}^{p}$ is the vector of all subcell inelastic strain components, $\alpha_{s}$ is the vector of all subcell coefficients of thermal expansion (CTEs), and $\mathbf{A}$ and $\mathbf{D}$ are strain concentration matrices. From eq. (2) the effective thermo-elastoplastic constitutive equations for an arbitrary periodic material, that are required to simulate the response of the composite material to external loading, can easily be determined (Aboudi, 1995). Clearly, in this original formulation of GMC, the subcell strains, $\varepsilon_{s}$, serve as the basic unknown quantities. Further, in solving eq. (1) for these quantities, a great deal of computational effort may be required as the matrix $\tilde{\mathbf{A}}$ becomes large as the number of subcells in the analyzed unit cell increases.

The recent reformulation of the GMC equations (Pindera and Bednarcyk, 1999; Bednarcyk and Pindera, 2000) employs subcell stresses (rather than strains) as basic unknowns and develops mixed concentration equations for the heterogeneous material. Due to GMC's inherent lack of normal-shear field coupling, significantly fewer unique subcell stress components are present compared to subcell strain components (see Pindera and Bednarcyk (1999) and Bednarcyk and Pindera (2000) for details). Tracking only the unique subcell stress components gives rise to,

$$
\tilde{\mathbf{G}} \mathbf{T}=\mathbf{f}^{m}-\mathbf{f}^{t}-\mathbf{f}^{p},
$$

which replaces eq. (1). Here, $\tilde{\mathbf{G}}$ is a matrix containing information on the repeating unit cell geometry and the properties of the constituent materials, $\mathbf{T}$ is the vector of all unique subcell stress components and $\mathbf{f}^{m}, \mathbf{f}^{t}$, and $\mathbf{f}^{p}$ are vectors containing global total strains, subcell thermal strains, and subcell inelastic strains, respectively. Solving eq. (3) provides mixed concentration equations,

$$
\mathbf{T}=\mathbf{G} \bar{\varepsilon}+\Gamma \Delta T+\boldsymbol{\Phi},
$$

where the thermal and inelastic terms are included in $\Gamma$ and $\Phi$, respectively. These are mixed concentration equations because they provide local stresses in terms of global strains; $\mathbf{G}$ (which is the inverse of $\tilde{\mathbf{G}}$ ) is the mixed concentration matrix. Clearly, since there are far fewer unique subcell stress components than strain components, a significant improvement in efficiency is gained by employing the 
reformulation of GMC. Thus, by exploiting GMC's lack of shear coupling, the reformulation represents an ultra-efficient multi-axial micromechanics analysis tool. Direct comparison of execution times resulting from the reformulated and original versions of GMC indicates a striking speed-up associated with the reformulation, particularly as the number of subcells becomes large. For example, for a $12 \times 12$ subcell repeating unit cell, the reformulated version of GMC has been shown to be more than 19,000 times faster (Bednarcyk and Arnold, 2000a). As demonstrated by Pindera and Bednarcyk (1999), the original formulation and reformulation of GMC yield identical results, thus the speed-up comes with no loss of accuracy. Clearly, utilization of the reformulation is crucial to the realization of reasonable execution times for application of GMC to detailed composite microstructures and when embedded within lamination theory to represent the material response at an integration point. In fact, most of the results generated for this study could not have been generated (due to exorbitant execution times) prior to the reformulation of GMC.

In order to simulate the response of composite laminates, the reformulated version of GMC has been embedded within classical lamination theory, as shown in Fig. 2. The basic thermo-elastic lamination theory equations are operable (see Jones, 1968) with the additional terms that represent the effects of inelastic strains. The overall laminate constitutive equation can then be written,

$$
\left[\begin{array}{cc}
\overline{\mathbf{A}} & \overline{\mathbf{B}} \\
\overline{\mathbf{B}} & \overline{\mathbf{D}}
\end{array}\right]\left[\begin{array}{l}
\boldsymbol{\varepsilon}^{0} \\
\boldsymbol{\kappa}
\end{array}\right]=\left[\begin{array}{c}
\mathbf{N} \\
\mathbf{M}
\end{array}\right]+\left[\begin{array}{c}
\mathbf{N}^{T} \\
\mathbf{M}^{T}
\end{array}\right]+\left[\begin{array}{c}
\mathbf{N}^{i n} \\
\mathbf{M}^{i n}
\end{array}\right]
$$

where $\overline{\mathbf{A}}, \overline{\mathbf{B}}$, and $\overline{\mathbf{D}}$ are the extension, coupling, and bending stiffness matrices, $\boldsymbol{\varepsilon}^{0}$ is the vector of midplane strain components, $\boldsymbol{\kappa}$ is the vector of midplane curvatures, $\mathbf{N}$ and $\mathbf{M}$ are the mechanical force and moment resultant vectors, $\mathbf{N}^{T}$ and $\mathbf{M}^{T}$ are the thermal force and moment vectors, and $\mathbf{N}^{i m}$ and $\mathbf{M}^{i m}$ are the inelastic force and moment vectors (for additional details see Bednarcyk and Pindera (1996) and Herakovich (1998)).

As indicated in Fig. 2, while the overall laminate response is dictated by eq. (5), the response of the composite material at each Gauss integration point within each layer is determined via GMC. The effective stiffness and CTEs of each layer, once properly transformed to the global (laminate) coordinate system via standard rotation equations, allow the determination of the $\overline{\mathbf{A}}, \overline{\mathbf{B}}$, and $\overline{\mathbf{D}}$ matrices and the thermal force and moment vectors (for a given temperature change). In the absence of inelasticity, the formulation would then be complete. Given laminate scale applied loading in terms of an appropriate combination of mechanical force and moment resultants and midplane strains and curvatures along with a temperature change, the global response of the laminate can be determined using eq. (5). However, in the presence of inelasticity, the model must constantly localize and homogenize as the loading is applied in an incremental fashion. That is, the laminate scale loading results in a stress and strain field at the integration points within each layer. These fields are transformed (via rotation) and passed to GMC, which further localizes the fields from the level of the unit cell to each individual subcell. Then, on this micro scale, the inelastic strains are determined via an arbitrary inelastic constitutive model, and homogenized to yield the cell (meso scale) inelastic strains. This inelastic strain field, once transformed to the laminate coordinate system, is representative of a particular integration point in a particular layer of the laminate. Finally, the inelastic field is integrated through the thickness of each layer and the inelastic force and moment vectors are determined via the appropriate lamination theory equations. As stated, this localization/homogenization process must occur at each increment of the applied loading. Further, for a local inelastic constitutive model that includes a consistency condition (such as the incremental plasticity theory employed herein), a number of equilibrium iterations are required at each loading increment to ensure that the consistency condition is met. 


\section{Constituent Response}

The composite material examined in this study consists of a Ti-15-3 matrix reinforced by continuous SCS-6 silicon carbide fibers. In order to determine the deformation response of the SiC/Ti15-3 composite, it is first necessary to incorporate sub-models for the behavior of the individual phases. Towards this end, the SCS-6 fiber was treated as an elastic, isotropic material with the temperaturedependent properties given in Table 1. The elastoplastic constitutive response of the Ti-15-3 matrix was modeled using Mendelson's (1968) time-independent incremental plasticity theory. This theory provides the inelastic strain increment for an isotropic material (with some manipulation of Mendelson's (1968) equations),

$$
d \varepsilon_{i j}^{i n}=\left(1-\frac{\bar{\sigma}_{e f f}}{3 G \varepsilon_{e r}}\right) e_{\imath j}^{\prime}
$$

where $G$ is the elastic shear modulus, $\varepsilon_{e}$ is the equivalent modified total strain deviator, and $e_{y j}^{\prime}$ are the components of the modified total strain deviator (see Mendelson (1968) for details). The final term appearing in eq. (6), $\bar{\sigma}_{e f f}$, is the effective stress. This term is determined from the post-yield hardening response of the material. Typically, the post-yield response of the material is taken to be bilinear (see Bednarcyk and Pindera (2000), Williams and Pindera (1997)), in which case the effective stress is given by,

$$
\bar{\sigma}_{e f f}=\sigma_{y}+\frac{E H}{E-H} \bar{\varepsilon}_{e f f}^{p}
$$

where $\bar{\varepsilon}_{\text {eff }}^{p}$ is the effective plastic strain and $H$ is the secondary, or post-yield, slope of the material's uniaxial stress-strain curve (approximated as bilinear). The present implementation of the incremental plasticity theory has been extended to admit piecewise linear post-yield behavior. This allows a more accurate representation of the actual inelastic material behavior as the response can be broken into an arbitrary number of linear sections. Then, in the $i^{\text {th }}$ linear section, the effective stress is given by,

$$
\bar{\sigma}_{e f f}=Y_{i-1}+H_{s p}\left(\bar{\varepsilon}_{e f f}^{p}-\bar{\varepsilon}_{i-1}^{p}\right)
$$

where $Y_{i}$ and $\bar{\varepsilon}_{i}{ }^{p}$ are points of stress and plastic strain along the piecewise linear representation of the uniaxial stress-strain curve, and $H_{s p}^{i}$ is the local slope of the curve. The plastic strain points of the piecewise linear representation are calculated from total strain points (which are actually input to the analysis code) from,

$$
\bar{\varepsilon}_{i}^{p}=\bar{\varepsilon}_{i}-\frac{Y_{i}}{E}
$$

where $\bar{\varepsilon}_{i}$ are the input strain points.

The temperature-dependent elastic properties for the Ti-15-3 matrix are given in Table 2 . The inelastic properties, in terms of yield stress and additional stress-strain point pairs, are given in Table 3. Figure 3 shows the characterization of the Mendelson incremental plasticity model for the Ti-15-3 matrix material (Tuttle and Rogacki (1991)). Clearly, the point-wise nature of the implementation has enabled the model to reproduce the temperature-dependent uniaxial stress-strain response of the material quite well. Linear interpolation is used to allow the properties to span the entire temperature range indicated. 


\section{UNIDIRECTIONAL COMPOSITE TENSILE RESPONSE}

In order to model the deformation, failure, and fatigue lives of $\mathrm{SiC} / \mathrm{Ti}-15-3$ laminates, two additional local effects, which pertain to the response of unidirectional SiC/Ti-15-3, must be considered. The first is interfacial debonding between the fiber and the matrix due to a local tensile normal stress. The second is breakage of individual fibers due to a local axial stress.

It is well known that unidirectional $\mathrm{SiC} / \mathrm{Ti}$ composites exhibit fiber-matrix debonding when subjected to off-axis loading (see Johnson et al. (1990), Mall and Nicholas (1998), and Bednarcyk and Arnold $(2000 \mathrm{~b})$ ). In order to capture even the qualitative nature of the off-axis SiC/Ti-15-3 tensile response, a simulation must account for this interfacial debonding (which typically causes a noticeable "knee" in the stress-strain curve). A model for interfacial debonding known as the evolving compliant interface (ECI) model was recently developed and implemented within GMC by Bednarcyk and Arnold (2000b). The ECI model employs the concept of a flexible interface (Jones and Whittier, 1967), wherein a discontinuity in the normal or tangential displacement component at an interface, $I$, is permitted. These discontinuities are taken to be proportional to the appropriate stress component at the interface such that,

$$
\begin{array}{ll}
{\left[u_{n}\right]^{I}=\left.R_{n} \sigma_{n}\right|^{I} ;} & \left.\sigma_{n}\right|^{I} \geq\left.\sigma_{D B}^{n}\right|^{I} \\
{\left[u_{t}\right]^{I}=\left.R_{t} \sigma_{t}\right|^{I} ;} & \left.\sigma_{t}\right|^{I} \geq\left.\sigma_{D B}^{\prime}\right|^{I}
\end{array}
$$

where $\left[u_{n}\right]^{l}$ and $\left[u_{t}\right]^{I}$ are the normal and tangential displacement discontinuities at the interface, $\left.\sigma_{n}\right|^{I}$ and $\left.\sigma_{t}\right|^{l}$ are the normal and tangential stress components at the interface, $R_{n}$ and $R_{t}$ are empirical debonding parameters that represent the effective compliance of the interface, and $\sigma_{D B}^{n}$ and $\sigma_{D B}^{\prime}$ are the normal and tangential debond stresses (i.e. strengths) of the interface. After debonding occurs, the ECI model allows interfacial debonding to progress through unloading of the stress at the interface by treating the debonding parameters as time-dependent. The form of this time-dependence is,

$$
R(t)=\Lambda\left[\exp \left(\frac{t-t_{D B}}{\mathrm{~B}}\right)-1\right] \quad t \geq t_{D B}
$$

where $\Lambda$ and $\mathrm{B}$ are empirical constants specific to the interface, $t$ is the time, and $t_{D B}$ is the time at which debonding occurs.

Bednarcyk and Amold (2000b) used GMC, with the ECI model functioning as a sub-model, to simulate the transverse tensile and creep response of SCS-6/TIMETAL 21S composites. In the present study, the ECI model (still functioning within GMC) was re-characterized for application to SCS-6/Ti-153. Further, Bednarcyk and Arnold (2000b) employed a $26 \times 26$ subcell repeating unit cell to represent a single refined fiber and allowed debonding to progress around the fiber during simulated loading. Herein the employed repeating unit cell contains 28 individual fibers, each with its own interfacial bond strengths and $\Lambda$ parameters. The bond strengths and parameters employed in the present study are given in Table 4. The parameters in Table 4 associated with normal debonding were characterized based on a comparison of GMC predictions with experiment for a room-temperature transverse tensile test on a $35 \%$ fiber volume fraction SCS-6/Ti-15-3. This characterization is shown in Fig. 4. Note that residual stresses from fabrication were included in the model simulations via application of a globally stress-free cool 
down (from an assumed stress-free temperature of $600{ }^{\circ} \mathrm{C}$ ) ${ }^{1}$ prior to application of the simulated tensile loading. The composite's simulated failure was accomplished using a global transverse maximum stress failure criterion of $429 \mathrm{MPa}$.

Due to the unavailability of experimental shear test results for SCS-6/Ti-15-3 and the need for capturing multiaxial effects, the parameters in Table 4 associated with tangential debonding were assembled using the normal debonding parameters as a starting point. Alterations were then made to better capture the qualitative nature of the $[ \pm 45]_{2 s}$ laminate deformation response. This correlation is shown in the next section.

The breakage of individual fibers that leads to the overall failure of longitudinally loaded unidirectional SiC/Ti composites also must be addressed via a sub-model. It is well known that the rule of mixtures type failure models, which assume that the composite's fibers fail when the average fiber stress reaches the average fiber strength, tend to over predict the strength of $\mathrm{SiC} / \mathrm{Ti}$ composites significantly (e.g., Brindley and Draper (1993). In reality, early breakage of individual lower strength fibers decreases the global stiffness of the composite and redistributes additional loads to the intact fibers, resulting in lower axial strengths. Curtin's (1991) effective fiber breakage model was employed to account for these effects. The Curtin model was recently incorporated within GMC by Bednarcyk and Arnold (2000a) and applied to model the longitudinal tensile response of SCS-6/TIMETAL 21S composites. Using fiber strength statistics combined with a shear-lag analysis, Curtin (1991) developed a general equation describing the stiffness degradation of an effective fiber that represents all fibers in the composite as the composite is loaded longitudinally. The effective fiber elastic modulus is given by,

$$
E_{f}^{*}=\frac{1}{2}\left\{1+\exp \left[-\left(\frac{E_{f} \varepsilon_{f}^{m e c h}}{\sigma_{c}}\right)^{m+1}\right]\right\} E_{f}
$$

where $E_{f}$ is the original fiber modulus, $\varepsilon_{f}^{\text {mech }}$ is the fiber longitudinal mechanical strain, $m$ is the fiber Weibull modulus, and $\sigma_{c}=\left(2 \sigma_{0}^{m} \tau L_{0} / d\right)^{1 /(m+1)}$. The term $\sigma_{0}$ is the mean fiber strength, $\tau$ is the frictional sliding resistance between the fiber and the matrix, $L_{0}$ is the fiber gauge length, and $d$ is the fiber diameter. The model predicts composite failure when the stress in the effective fiber reaches a maximum,

$$
\sigma_{f}^{\max }=\frac{1}{2} \sigma_{c} x^{1 /(m+1)}[1+\exp (-x)]
$$

where $x$ is the first positive integer that satisfies,

$$
1+[1-(m+1) x] \exp (-x)=0
$$

One limitation of the Curtin model (revealed by the off-axis laminate results shown later) is its uniaxial nature. However, for unidirectional $\mathrm{SiC} / \mathrm{Ti}$ composites loaded longitudinally, it is still quite capable of predicting stiffness degradation and failure when employed within GMC (Bednarcyk and Amold, 2000a).

Figure 5 compares the longitudinal tensile deformation and failure of SCS-6/Ti-15-3 composites as predicted by GMC with experimental results. The employed Curtin model parameters are:

\footnotetext{
${ }^{1}$ The $600^{\circ} \mathrm{C}$ stress-free temperature was selected based on correlation with experiment for the room temperature $41 \%$ SCS-6/Ti-15-3 tensile results shown in Fig. 5.
} 
$d=142 \mu \mathrm{m}, L_{0}=12.7 \mathrm{~mm}, m=17.0, \sigma_{0}=3.85 \mathrm{GPa}$ (from Draper et al., 1992), and $\tau_{0}=14 \mathrm{MPa}$ (from Bednarcyk and Arnold, 2000a). Since the implementation of the Curtin model did not include temperature-dependent model parameters, in order to account for the fiber strength degradation due to elevated temperature, for the $427{ }^{\circ} \mathrm{C}$ predictions, the $\sigma_{0}$ value was reduced by $3.5 \%$ (Bednarcyk and Arnold, 2000a). Since the Curtin model represents the behavior of all fibers within the composite as one effective fiber, a simple $2 \times 2 \mathrm{GMC}$ repeating cell containing a single fiber was employed.

The room temperature $41 \%$ SCS-6/Ti-15-3 results shown in Fig. 5 were employed to characterize the composite's stress-free temperature $\left(600^{\circ} \mathrm{C}\right)$. For this stress-free temperature, the deformation predicted by the model agrees well with experiment. The $427{ }^{\circ} \mathrm{C}$ results represent pure predictions. Examining the $427^{\circ} \mathrm{C}$ predictions for fiber volume fractions of $41 \%, 35 \%$, and $15 \%$, it is clear that the model under predicts the deformation somewhat, exhibiting a greater amount of inelastic deformation compared to experiment. This indicates that the residual stresses, as simulated by the model using the stress-free temperature of $600{ }^{\circ} \mathrm{C}$, are inexact (Goldberg and Arnold, 1999). This is expected as the matrix constitutive model is time-independent and thus does not allow any relaxation of residual stresses. The model still does a reasonably good job of predicting the composite UTS for these three fiber volume fractions. The results for the fiber volume fraction of $25 \%$, on the other hand, show a large discrepancy between model and experiment. The cause of this discrepancy is not known at this time, however, the experimental results exhibit much better agreement with model predictions for a composite with a fiber volume fraction of $28 \%$.

\section{LAMINATE TeNSILE ResPonse}

Using the information garnered from the tensile response of the unidirectional SCS-6/Ti-15-3 composites, the lamination theory implementation of GMC can be used to predict the tensile response of SCS-6/Ti-15-3 laminates. For the laminate, the coupled analysis spans three levels of scale. The global or structural scale problem is addressed using the lamination theory equations. The meso scale problem is represented by GMC, analyzing the behavior of the composite material at the integration points within each layer of the laminate. Finally, the micro scale consists of the individual fiber and matrix subcells within the GMC repeating unit cells at each integration point. On the micro scale, the equations of incremental plasticity, as well as the ECI debonding and Curtin fiber breakage models, are operative. This multi-scale analysis is coupled in the sense that during each increment of the applied loading and each equilibrium iteration, the entire scale is spanned through the localization and homogenization provided by the models. Further, the predictions of each model on each scale affect the predictions of the models functioning on the other scales.

The GMC repeating unit cells employed for each integration point in each layer of the laminate were identical to that employed for the transverse composite simulations. This unit cell consists of 28 fibers, which were assigned debonding parameters according to Table 4. In addition, the Curtin model was used to simulate the longitudinal stiffness degradation and breakage of the fibers. Since the Curtin model simulates many fibers as one effective fiber, identical Curtin model parameters (given above in Section 4) were employed.

Figure 6 compares model results with experiment (Lerch and Saltsman, 1993) for the deformation and failure of $[0 / 90]_{2 s},[ \pm 45]_{2 s}$, and $[ \pm 30]_{2 s}$ laminates along with the longitudinal and transverse (i.e., $[0]_{8}$ and $[90]_{8}$ ) results shown earlier. As mentioned previously, it was necessary to utilize the $[ \pm 45]_{2 s}$ results to determine the shear debonding parameters for the ECI model (see Table 4). Consequently, the deformation results of only the $[0 / 90]_{2 \mathrm{~s}}$ and $[ \pm 30]_{2 \mathrm{~s}}$ laminate should be viewed as predictions. Further, a repeating unit cell level maximum shear stress failure criterion of $220 \mathrm{MPa}$ (chosen based on correlation) was employed in the simulations. Clearly, the model agrees quite well with the laminate experiments. Figure 7, however, shows that the GMC model prediction is somewhat quantitatively inaccurate for a $[ \pm 60]_{2 s}$ laminate. While the experimental stress-strain curve for this laminate falls below the curve for the $[90]_{8}$ composites, GMC predicts (as one might expect) that the $[ \pm 60]_{s}$ laminate curve falls above that of 
the $[90]_{8}$ composite. Qualitatively, the predicted curve is quite good as it resembles the experimental curve closely. The specific stages of the laminate deformation, involving strong bonding with elastic behavior, followed by debonding, and finally by large-scale inelastic behavior, are well represented (see Bednarcyk and Arnold, 2000b). The quantitative discrepancy is likely due to inadequacies of the GMC model in terms of shear (i.e., its lack of normal-shear field coupling). Further, the shear debonding parameters could be altered to provide better correlation with experiment in Fig. 7, however, this would affect the agreement between model and experiment for the $[ \pm 45]_{2 \mathrm{~s}}$ laminate in Fig. 6 .

\section{LAMINATE LOW CYCLE FATIGUE RESPONSE}

With the illustrated ability of GMC to model the deformation and static failure response of $\mathrm{SiC} / \mathrm{Ti}-15-3$ laminates, the LCF life of the composite can now be addressed using an appropriate local fatigue damage model. Towards this end, the multiaxial, isothermal, continuum damage mechanics model of Arnold and Kruch (1994) has been employed. This model was previously incorporated within GMC by Wilt et al. (1997). It assumes a single scalar internal damage variable, $D$, that has a value of zero for undamaged material and one for a completely damaged (failed) material. A summary of the damage model equations is given in the appendix.

The implementation of the damage model within GMC has been performed on the local scale, thus damage evolves in a given subcell based on the local stress state and number of cycles. For a given damage level, the stiffness of the subcell is degraded by $(1-D)$, while the inelastic strains are calculated using an effective stress that is increased by the factor $1 /(1-D)$. Further, the GMC implementation allows the application of a local damage increment, $\Delta D$, and then calculates the number of cycles, $N$, required to achieve this local increment of damage. This approach allows the model to determine the stress state in the composite, identify the subcell that will reach the desired damage level in the fewest cycles, apply that number of cycles, and calculate the damage that arises throughout the remainder of the composite. Then the composite can be reanalyzed and a new stress state determined based on the new damage level throughout the composite. In this way the local and global stress and damage analyses are coupled. As the damage in the composite evolves, the stress field in the composite is redistributed, which then affects the evolution of damage.

The damage model was characterized for the isotropic Ti-15-3 matrix at $427^{\circ} \mathrm{C}$. Given the fact that the specific material is isotropic, the parameters $\omega_{n}, \omega_{f}, \omega_{m}, \eta_{n}, \eta_{f}$, and $\eta_{m}$ are set equal to one, and the model summarized in the appendix reduces to the well-known ONERA NLCDM model (Chaboche and Lesne (1988), Lemaitre and Chaboche (1990)). The parameters $\beta, \hat{a}, \sigma_{f}^{0}, M_{0}$, and $\sigma_{u}$ were selected based on correlation with matrix data for fully reversed stress controlled fatigue tests (i.e., the mean stress, $\bar{\sigma}=0$ and $R=\sigma_{\min } / \sigma_{\text {max }}=-1$ ). This correlation is shown in Fig. 8. The parameters $b$ and $b^{\prime}$ determine the mean stress dependence of the damage model parameters $M$ and $\sigma_{f}$ such that,

$$
\begin{gathered}
M=M_{0}(1-b \bar{\sigma}) \\
\sigma_{f l}=\sigma_{f l}^{0}\left(1-b^{\prime} \bar{\sigma}\right)
\end{gathered}
$$

The correlation for selecting $b$ and $b^{\prime}$, based on experiments with $\bar{\sigma}=0$, is shown in Fig. 9. Note that the model results in Figs. 8 and 9 are purely from the damage model, GMC was not involved in these calculations.

In the case of the elastic fiber, a simple strength degradation damage model (which is intended to account for interfacial and fiber damage due to repeated cyclic loading), in accordance with the study by Wilt et al. (1997), was implemented for the SCS-6 fiber. This type of model was introduced rather than using the previous fatigue damage model since no marked change in the stiffness of the fiber due to cyclic 
loading is experimentally observed. This implementation involved degradation of the Curtin model fiber strength parameter, $\sigma_{0}$, with the number of applied fatigue cycles, $N$. Correlation, performed using longitudinal LCF life results, yielded the following degradation equation for $\sigma_{0}$,

$$
\begin{array}{ccc}
\sigma_{0}=3.72 \mathrm{GPa} & N<10,000 \\
\sigma_{0}=11.8-2.02 \log (N) \mathrm{GPa} & 10,000 \leq N \leq 23,263 \\
\sigma_{0}=2.98 \mathrm{GPa} & N>23,263
\end{array}
$$

This form and these values were chosen based on correlation using the $[0]_{8}$ experimental data shown in Fig. 10.

Using the above-described damage models for the fiber and matrix, the Mendelson incremental plasticity for the matrix inelastic behavior, the ECI model for the normal and tangential debonding at the fiber-matrix interface, and the Curtin model for the longitudinal breakage of the fiber, GMC was employed to predict the LCF life of $[ \pm 30]_{2 \mathrm{~s}}$ and $[ \pm 45]_{2 \mathrm{~s}}$ laminates, as well as the transverse $[90]_{8}$ composite at $427^{\circ} \mathrm{C}$. The results are shown in Fig. 10. Generation of the shown model predictions was quite intense from a computational standpoint as each of the two integration points in each of the three layers of the laminate was represented by a GMC unit cell consisting of 28 fibers (112 subcells). A globally stress-free cool down from $600^{\circ} \mathrm{C}$ to room temperature, followed by a globally stress-free heat up to $427^{\circ} \mathrm{C}$, was applied prior to application of the simulated applied loading cycle. Recall that due to the presence of plasticity, the loading was applied incrementally with equilibrium iterations required for each increment. The loading cycle was then repeated for each applied local damage increment until complete failure of the laminate, resulting from an accumulation of local and meso scale failures, occurred. Typically, a local damage increment of 0.2 was employed, the loading cycle was broken into 240 total increments, an average of 20 equilibrium iterations were required for convergence, and execution of the model (for each $\sigma_{m}$ value) took in the range of 10 to 20 minutes $^{2}$ on a $700 \mathrm{MHz}$ Pentium III personal computer. Considering the complexities of this multiscale approach and the number of variables the simulations required, the authors regard the model's execution as being quite efficient, especially when compared to the alternatives available for such an analysis.

It is clear from Fig. 10 that GMC, with its incorporated micro scale models, does quite a good job of matching with the experimental data (Lerch (1990) and Lerch et al. (1993)) for this complex problem. The $[90]_{8},[ \pm 45]_{2 s}$, and $[ \pm 30]_{2 s}$ model results are pure predictions, while, as described above, the $[0]_{8}$ results have been correlated below a stress level of $1.04 \mathrm{GPa}$. The agreement with experiment for the $[ \pm 45]_{2 s}$ laminate is remarkable. For the $[ \pm 30]_{2 s}$ laminate, the agreement appears to be good in the higher life (low stress) range. However, as the predicted cycles to failure decrease, the stress increases to a much greater degree than in the experimental data. That is, the typical "step" in the predicted S-N curve is too severe, and the life is over predicted for the higher stresses. This discrepancy is likely due (in some degree) to the uniaxial nature of the Curtin fiber breakage model since the Curtin model is dependent only upon the axial stress in the effective fiber, which is decreased significantly in the $[ \pm 30]_{2 \mathrm{~s}}$ laminate compare to the $[0]_{8}$ composite. Whereas, in reality, the off-axis stresses, which are significant in the $[ \pm 30]_{2 s}$ laminate, should contribute to the fiber breakage. In the $[ \pm 30]_{2 \mathrm{~s}}$ laminate tensile response, this problem was overcome by employing a meso scale maximum shear stress criterion (see Fig. 6). However, this criterion activates only for the highest applied stress, leading to a life of only 1 cycle in Fig. 10. This is clearly not a problem for the $[ \pm 45]_{2 \mathrm{~s}}$ laminate, whose behavior is more matrix and interface dominated. Additional potential explanations for the discrepancy in the $[ \pm 30]_{2 s}$ results include increased fiber damage due to the off-axis fiber orientation and inaccuracy of the matrix stress field due GMC"s lack of normal-shear coupling.

\footnotetext{
${ }^{2}$ Note that the executed cases were not consciously optimized for speed.
} 
In contrast to the $[ \pm 30]_{25}$ laminate prediction is the $[90]_{8}$ composite prediction, which appears to be in good agreement with experiment for the lower life range, but poor agreement in the higher life range. The predicted S-N curve is clearly too flat. The $[90]_{8}$ composite is dominated to the greatest extent by the matrix and interface behavior, and thus this discrepancy is likely due to inaccuracies associated with the matrix constitutive model (time-independent plasticity) and the ECI debonding model. In addition, once complete debonding of the fiber-matrix interfaces in the composite has occurred, it is as if the composite contains holes (rather than fibers), which give rise to stress concentrations in the matrix and lower fatigue life. Such stress concentrations are not well represented by GMC due to the averaging performed in the method's formulation. This would tend to cause GMC to over predict the life of the $[90]_{8}$ composite as illustrated in Fig. 10 . Considering the complexities associated with predicting the LCF life of these laminates along with the approximate or effective nature of many of the modeling approaches employed, the overall agreement between model and experiment exhibited in Fig. 10 must be considered to be very good.

\section{Conclusion}

A fully coupled deformation and damage approach to modeling the response of composite materials and composite laminates has been presented. It is based on the analytical GMC micromechanics model, which provides closed-form constitutive equations for composite materials as well as the micro scale stress and strain fields in the composite phases. The provided constitutive equations allow GMC to function within a higher scale structural analysis to represent a composite material point, while the availability of the micro fields allows the incorporation of lower scale submodels to represent local phenomena in the fiber and matrix. Further, GMC's formulation performs averaging when applying certain governing equations, such that some degree of micro scale field accuracy is surrendered in favor of extreme computational efficiency, rendering the method quite attractive as the centerpiece in a multiscale structural analysis.

This approach has been applied to simulate the deformation, static failure, and LCF life of $\mathrm{SiC} / \mathrm{Ti}-15-3$ composites. The important effects of residual stresses, matrix inelasticity, fiber breakage, and fiber-matrix debonding have been incorporated within GMC through appropriate sub-models and load histories. For the LCF calculations, an appropriate continuum damage fatigue model was incorporated on the micro scale as well. For simulations of composite laminates, GMC, with all its submodels intact, was embedded within lamination theory, which served as the global or structural scale model. The approach then spanned three fully coupled levels of scale for each iteration of each increment of the applied simulated loading. Results from the GMC model were compared with experiment and exhibited good agreement for the deformation, static failure, and LCF life of the SCS-6/Ti-15-3 composite materials and laminates. This type of multiscale analysis of composites and composite structures shows promise for future design and optimization tools. 


\section{REFERENCES}

Aboudi, J., 1991. Micromechanics of Composite Materials: A Unified Micromechanical Approach. Elsevier, Amsterdam.

Aboudi, J., 1995. Micromechanical Analysis of Thermo-Inelastic Multiphase Short-Fiber Composites. Composites Engineering 5 (7), 839-850.

Amold, S.M., Arya, V.K., Melis, M.E., 1990. Elastic/Plastic Analyses of Advanced Composites Investigating the Use of the Compliant Layer Concept in Reducing Residual Stresses Resulting from Processing. NASA-TM-103204.

Amold, S.M., Bednarcyk, B.A., Wilt, T.E., Trowbridge, D., 1999. MAC/GMC User Guide: Version 3.0. NASA/TM-1999-209070.

Arnold, S.M., Kruch, S., 1994. Differential Continuum Damage Mechanics Models for Creep and Fatigue of Unidirectional Metal Matrix Composites. International Journal of Damage Mechanics 3 (2), 170-91.

Arnold, S.M. and Castelli, M.G., 1995. What Constitutes a Model Material?, HITEMP Review 1995, Vol. II, NASA CP 10178, paper 35A.

Bednarcyk, B.A., Amold, S.M., 2000a. A New Local Failure Model With Application to the Longitudinal Tensile Behavior of Continuously Reinforced Titanium Composites. NASA/TM-2000-210027, see also Composite Science and Technology 61, 2001, 705-729.

Bednarcyk, B.A., Arnold, S.M., 2000b. Transverse Tensile and Creep Modeling of Continuously Reinforced Titanium Composites with Local Debonding NASA/TM-2000-210029, see also International Journal of Solids and Structures, 2001, In Press.

Bednarcyk, B.A., Pindera, M.-J., 1996. Inelastic Thermal Response of $\mathrm{Gr} / \mathrm{Cu}$ with Nonuniform Fiber Distribution. Journal of Aerospace Engineering 9 (4), 93-105.

Bednarcyk, B.A., Pindera, M.-J., 2000. Inelastic Response of a Woven Carbon/Copper Composite - Part II: Micromechanics Model. Journal of Composite Materials 34 (4), 299-331.

Brindley, P.K. and Draper, S.L., 1993. Failure Mechanisms of $0^{\circ}$ and $90^{\circ} \mathrm{SiC} / \mathrm{Ti}-24 \mathrm{Al}-11 \mathrm{Nb}$ Composites Under Various Loading Conditions, Structural Intermetallics, Ed. Darolia, R., Lewandowski J.J., Liu C.T., Martin, P.L., Miracle, D.B. and Nathal, M.V., The Minerals, Metals \& Materials Society.

Chaboche, J.L. and Lesne, P.M., 1988. A Non-Linear Continuous Fatigue Damage Model, Fatigue Fract. Engng. Mater. Struct., Vol. 11, No. 1, pp. 1-7.

Clyne, T.W., and Withers, P.J., 1993. An Introduction to Metal Matrix Composites, Cambridge University Press.

Curtin, W.A., 1991. Theory of Mechanical Properties of Ceramic-Matrix Composites. Journal of the American Ceramics Society 74 (11), 2837-45.

Draper, S.L., Brindley, P.K., Nathal, M.V., 1992. The Effect of Fiber Strength on the Room Temperature Tensile Properties of SiC/Ti-24AI-1 1Nb. Metallurgical Transactions A 23A, 2541-48. 
Goldberg R.K., Arnold, S.M., 1999. A Study of Influencing Factors on the Tensile Response of a Titanium Matrix Composite with Weak Interfacial Debonding. NASA/TM-1999-209798.

Herakovich, C. T., 1998. Mechanics of Fibrous Composites, John Wiley \& Sons, Inc.

Johnson, W.S., Lubowinski, S.J., Highsmith, A.L., 1990. Mechanical Characterization of SCS-6/Ti-15-3 Metal Matrix Composites at Room Temperature. Thermal and Mechanical Behavior of Ceramic and Metal Matrix Composites, ASTM STP 1080, J.M. Kennedy, H.H. Moeller, and W.S. Johnson (Eds.), 193218.

Jones, J.P., Whittier, J.S., 1967. Waves at Flexibly Bonded Interfaces. Journal of Applied Mechanics 34, 905-909

Lerch, B.A., 1990. Fatigue Behavior of SiC/Ti-15-3 Laminates. HiTemp Review 1990, NASA CP 10051 , pp. 35-1 to $35-9$.

Lerch, B.A., Saltsman, J.F., 1993. Tensile Deformation of SiC/Ti-15-3 Laminates. Composite Materials: Fatigue B and Fracture, Fourth Volume, ASTM STP 1156, eds. W.W. Stinchcomb and N.E. Ashbaugh, ASTM, Philadelphia, pp. 161-175.

Lerch B.A., Verrilli, M.J., and Halford, G.R., 1993. Fully Reversed Fatigue of a Ti-MMC, Proceeding of the American Society For Composites $-8^{\text {th }}$ Technical Conf., Cleveland, $\mathrm{OH}$.

Lemaitre, J. and Chaboche, J.L., 1990. Mechanics of Solid Materials, Cambridge University Press.

Mall, S. and Nicholas, T., 1998. Titanium Matrix Composites, Mechanical Behavior, Technomic.

Mendelson, A., 1983. Plasticity: Theory and Application, Krieger Publishing Co.

Pindera, M.-J., Bednarcyk, B.A., 1999. An Efficient Implementation of the Generalized Method of Cells for Unidirectional, Multi-Phased Composites with Complex Microstructures. Composites Part B 30 (1), 87-105.

Rosenberg, H.W., 1993. Ti-15-3 Property Data. Proceedings of Beta Titanium Alloys in the 80's, R.R. Boyer and H.W. Rosenberg (Eds.), Metallurgical Society, Atlanta.

Tuttle, M.E. and Rogacki, J., 1991. Thermoviscoplastic Response of Ti-15-3 Under Various Loading Conditions, NASA CR 187621.

Williams, T.O., Pindera, M.-J., 1997. An Analytical Model For The Inelastic Axial Shear Response of Unidirectional Metal Matrix Composites, Int. Jnl. of Plasticity, Vol. 13, No. 3, pp. 261-289.

Wilt, T.E., Arnold, S.M., Saleeb, A.F., 1997. A Coupled/Uncoupled Computational Scheme for Deformation and Fatigue Damage Analysis of Unidirectional Metal-Matrix Composites. Applications of Continuum Damage Mechanics to Fatigue and Fracture, ASTM STP 1315, D.L. McDowell (Ed.), 65-82. 



\section{APPENdix: Fatigue Damage Model}

For additional details on the fatigue damage model, see Arnold and Kruch (1994) and Wilt et al. (1997). The evolution of damage is governed by,

$$
\int_{D_{k-1}}^{D_{k}} d D=\int_{0}^{N}\left[1-(1-D)^{\beta+1}\right]^{\alpha}\left[\frac{\hat{F}_{m}}{1-D}\right]^{\beta} d N
$$

where $N$ is the number of cycles at the current stress state $\left(\sigma_{k}\right), D_{k}$ and $D_{k-1}$ are the amount of damage after the current and previous damage increments, respectively, and $\alpha$ is a function of the current stress state,

$$
\alpha=1-\hat{a} \frac{\sigma_{n l}}{\sigma_{n}} \frac{\left\langle\Phi_{f l}\right\rangle}{\left\langle\Phi_{n}\right\rangle}
$$

and \langle\rangle are Macauley brackets. $\sigma_{f}$ and $\sigma_{11}$ are the uniaxial fatigue limit and ultimate strength (see eq 16 and Table 5), respectively, and $\Phi_{f}$ and $\Phi_{u}$ are the fatigue limit and static fracture surfaces, respectively,

$$
\begin{gathered}
\Phi_{f}=\frac{1}{2} \frac{\max }{t_{0}} \frac{\max }{t} F_{\left(\sigma_{f}\right)}\left[\sigma_{i j}(t)-\sigma_{i j}\left(t_{0}\right)\right]-1 \\
\Phi_{u}=1-\frac{\max }{t} F_{\left(\sigma_{n}\right)}\left[\sigma_{i j}(t)\right]
\end{gathered}
$$

and the normalized stress amplitude is defined as,

$$
\hat{F}_{m}=\frac{1}{2} \frac{\max }{t} \frac{\max }{t_{0}} F_{(M)}\left[\sigma_{i j}(t)-\sigma_{i j}\left(t_{0}\right)\right]
$$

When $\left\langle\Phi_{n}\right\rangle=0$, static fracture (complete local failure) is indicated, thus $\alpha$ cannot be undefined. $\left\langle\Phi_{f\rangle}\right\rangle=0$ indicates that the current stress state is below the fatigue limit and $\alpha$ is set to one. This then represents a special case when integrating eq. (A1) that will be considered separately. The $t_{0}$ and $t$ terms in eqs. (A3 - A5) are the time at the beginning of the current load cycle and some time during the current load cycle, respectively. The operator $\frac{\max }{t}$ indicates that the maximum value of the expression to the right up to time $t$ of the current load cycle should be taken.

The general form for the terms $F_{\left(\sigma_{\ell}\right)}, F_{\left(\sigma_{u}\right)}$, and $F_{(M)}$ can be expressed as,

$$
F_{()}=\sqrt{\frac{1}{()_{L}^{2}}\left[\left(4 \omega_{()}^{2}-1\right) I_{1}+\frac{4 \omega_{()}^{2}-1}{\eta_{()}^{2}} I_{2}+\frac{9}{4} I_{3}\right]}
$$


where,

$$
\begin{aligned}
& I_{1}=\frac{1}{2} S_{i j} S_{i j}-d_{i} d_{j} S_{j k} S_{k i}+\frac{1}{4}\left(d_{i} d_{j} S_{i j}\right)^{2} \\
& I_{2}=d_{i} d_{j} S_{j k} S_{k j}-\left(d_{i} d_{j} S_{i j}\right)^{2} \\
& I_{3}=\left(d_{i} d_{j} S_{i j}\right)^{2}
\end{aligned}
$$

The current deviatoric stress components are $S_{i j}=\sigma_{i j}-\frac{1}{3} \sigma_{m m} \delta_{i j}$, and $d_{1}$ are the components of the vector defining the preferred direction in a transversely isotropic material. $\omega_{1}$, and $\eta_{1}$, represent the ratios of longitudinal to transverse normal and shear stresses, respectively, for a transversely isotropic material and are equal to one for the current isotropic material (Ti-15-3) application.

For the case in which the current local stress state, $\sigma_{k}$, is above the initial fatigue limit, the number of cycles, $N$, required to damage a subcell from a level of $D_{k-1}$ to $D_{k}$ is obtained by integrating eq. (A1) and is given by,

$$
N=\frac{\left\{\left[1-\left(1-D_{k}\right)^{\beta-1}\right]^{1-\alpha}-\left[1-\left(1-D_{k-1}\right)^{\beta+1}\right]^{1-\alpha}\right\}}{\hat{F}_{m}^{\beta}(1-\alpha)(\beta+1)}
$$

When the local stress level is below the fatigue limit, $\alpha=1$, integration of eq. (A1) yields,

$$
N=\frac{\log \left[1-\left(1-D_{k}\right)^{\beta-1}\right]-\log \left[1-\left(1-D_{k-1}\right)^{\beta+1}\right]}{\hat{F}_{m}^{\beta}(\beta+1)}
$$

Equations (A8) and (A9) can also be solved for $D_{k}$ in order to determine the current amount of damage developed for a given number of cycles and previous state of damage, $D_{k-1}$. Further, to determine the remaining cycles to failure for a given previous state of damage, $D_{k}$ can be set equal to one in eqs. (A8) and (A9). 
Table 1. Temperature-dependent elastic properties for the SCS-6 fiber (Bednarcyk and Arnold, 2000a).

\begin{tabular}{|c|c|c|c|}
\hline $\mathbf{T}\left({ }^{\circ} \mathbf{C}\right)$ & $\mathbf{E}(\mathbf{G P a})$ & $v$ & $\alpha\left(\times 10^{-6} /{ }^{\circ} \mathbf{C}\right)$ \\
\hline 21. & 393. & 0.25 & 3.56 \\
\hline 316. & 382. & 0.25 & 3.73 \\
\hline 427. & 378. & 0.25 & 3.91 \\
\hline 538. & 374. & 0.25 & 4.07 \\
\hline 860. & 368. & 0.25 & 4.57 \\
\hline
\end{tabular}

Table 2. Temperature-dependent elastic properties employed for the Ti-15-3 matrix (Rosenberg, 1983).

\begin{tabular}{|c|c|c|c|}
\hline $\mathbf{T}\left({ }^{\circ} \mathbf{C}\right)$ & $\mathbf{E}(\mathbf{G P a})$ & $\boldsymbol{v}$ & $\alpha\left(\times \mathbf{1 0}^{-6}{ }^{\circ} \mathbf{C}\right)$ \\
\hline 23.9 & 89.52 & 0.3 & 8.33 \\
\hline 204.4 & 86.38 & 0.3 & 8.70 \\
\hline 315.6 & 78.89 & 0.3 & 9.13 \\
\hline 482.2 & 74.72 & 0.3 & 9.63 \\
\hline 565.6 & 71.12 & 0.3 & 9.88 \\
\hline 648.9 & 65.70 & 0.3 & 10.23 \\
\hline
\end{tabular}

Table 3. Piecewise linear, temperature-dependent inelastic data for the Ti-15-3 matrix determined via correlation with experiment (see Fig. 3).

\begin{tabular}{|c|c|c|c|c|c|c|c|c|c|c|c|}
\hline \multirow{2}{*}{\multicolumn{2}{|c|}{ 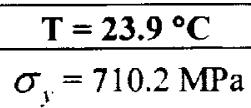 }} & \multicolumn{2}{|c|}{$T=204.4^{\circ} \mathrm{C}$} & \multicolumn{2}{|c|}{$T=315.6^{\circ} \mathrm{C}$} & \multicolumn{2}{|c|}{$T=482.2^{\circ} \mathrm{C}$} & \multicolumn{2}{|c|}{$T=565.6^{\circ} \mathrm{C}$} & \multicolumn{2}{|c|}{$T=648.9^{\circ} \mathrm{C}$} \\
\hline & & $\sigma_{1}=5$ & $.8 \mathrm{MPa}$ & $\sigma_{y}=$ & $.5 \mathrm{MPa}$ & $\sigma_{y}=4$ & $.0 \mathrm{MPa}$ & $\sigma_{y}=2$ & $.2 \mathrm{MPa}$ & $\sigma_{y}=$ & $\mathrm{MPa}$ \\
\hline $\begin{array}{c}\mathrm{Y} \\
(\mathrm{MPa})\end{array}$ & $\bar{\varepsilon}_{i}(\%)$ & $\begin{array}{c}\mathrm{Y} \\
(\mathrm{MPa})\end{array}$ & $\bar{\varepsilon}_{i}(\%)$ & $\begin{array}{c}\mathrm{Y} \\
(\mathrm{MPa})\end{array}$ & $\overline{\bar{\varepsilon}_{l}(\%)}$ & $\begin{array}{c}\mathrm{Y} \\
(\mathrm{MPa})\end{array}$ & $\bar{\varepsilon}_{i}(\%)$ & $\begin{array}{c}\mathrm{Y} \\
(\mathrm{MPa})\end{array}$ & $\overline{\bar{\varepsilon}_{i}(\%)}$ & $\begin{array}{c}\mathrm{Y} \\
(\mathrm{MPa})\end{array}$ & $\bar{\varepsilon}_{i}(\%)$ \\
\hline 786.0 & & 6 & & 572.3 & & 499.9 & 88 & 239.9 & .379 & 142.0 & 0.303 \\
\hline 799.8 & & 663.3 & 9 & 609.5 & 1.00 & 517. & 0.995 & 252.4 & 0.505 & 155.1 & 0.480 \\
\hline 813.6 & & 696.4 & & 641.9 & 8 & 518.5 & 1.50 & 255.1 & 1.01 & 163.4 & 0.976 \\
\hline 820.5 & 2.01 & 717.1 & 2.18 & 662.6 & 2.02 & 518.8 & 2.00 & 259.3 & 2.04 & 165.5 & 1.97 \\
\hline
\end{tabular}


Table 4. ECI model parameters of the 28 fibers in the composite GMC repeating unit cell.

\begin{tabular}{|c|c|c|c|c|}
\hline Fiber Number & $\sigma_{D B}^{n}(\mathrm{MPa})$ & $\Lambda_{n}\left(\mathrm{GPa}^{-1}\right)$ & $\sigma_{D B}^{\prime}(\mathrm{MPa})$ & $\Lambda,\left(\mathrm{GPa}^{-1}\right)$ \\
\hline 1 & 6.9 & 14.5 & 6.9 & 14.5 \\
\hline 2 & 20.7 & 13.1 & 20.7 & 13.1 \\
\hline 3 & 41.4 & 11.6 & 34.5 & 11.6 \\
\hline 4 & 69.0 & 10.2 & 48.3 & 7.25 \\
\hline 5 & 82.7 & 2.90 & 69.0 & 1.45 \\
\hline 6 & 138. & 0.725 & 148. & 1.02 \\
\hline 7 & 159. & 0.435 & 159. & 1.02 \\
\hline 8 & 186. & 0.290 & 169. & 0.870 \\
\hline 9 & 207. & 0.218 & 179. & 0.870 \\
\hline 10 & 262. & 0.218 & 190. & 0.725 \\
\hline 11 & 269. & 0.218 & 200. & 0.725 \\
\hline 12 & 276. & 0.218 & 210. & 0.580 \\
\hline 13 & 290. & 0.174 & 221. & 0.580 \\
\hline 14 & 303. & 0.174 & 231. & 0.435 \\
\hline 15 & 324. & 0.174 & 241. & 0.290 \\
\hline 16 & 338. & 0.174 & 252. & 0.145 \\
\hline 17 & 359. & 0.174 & 262. & 0.145 \\
\hline 18 & 386 & 0.174 & 272. & 0.116 \\
\hline 19 & 413. & 0.145 & 283. & 0.101 \\
\hline 20 & 441. & 0.131 & 293. & 0.0870 \\
\hline 21 & 469. & 0.0870 & 303. & 0.0580 \\
\hline 22 & 496. & 0.0870 & 314. & 0.0435 \\
\hline 23 & 552. & 0.0580 & 324. & 0.0290 \\
\hline 24 & 607. & 0.0435 & Strong & - \\
\hline 25 & 690. & 0.0435 & Strong & - \\
\hline 26 & 758. & 0.0261 & Strong & - \\
\hline 27 & 1000 & 0.0131 & Strong & - \\
\hline 28 & Strong & - & Strong & - \\
\hline
\end{tabular}


Table 5. Damage model parameters for the isotropic Ti-15-3 matrix.

\begin{tabular}{|c|c|c|}
\hline parameter & value & Units \\
\hline$b$ & 0.0 & - \\
\hline$b^{\prime}$ & 0.018 & - \\
\hline$\omega_{w}$ & 1.0 & - \\
\hline$\omega_{f}$ & 1.0 & - \\
\hline$\omega_{m}$ & 1.0 & - \\
\hline$\eta_{u}$ & 1.0 & - \\
\hline$\eta_{f}$ & 1.0 & - \\
\hline$\eta_{m}$ & 1.0 & - \\
\hline$\beta$ & 1.0 & - \\
\hline$\hat{a}$ & 0.0022 & $\mathrm{MPa}$ \\
\hline$\sigma_{n}^{0}$ & 207. & $\mathrm{GPa}$ \\
\hline$M_{0}$ & 12.4 & $\mathrm{MPa}$ \\
\hline$\sigma_{u}$ & 725. & \\
\hline
\end{tabular}




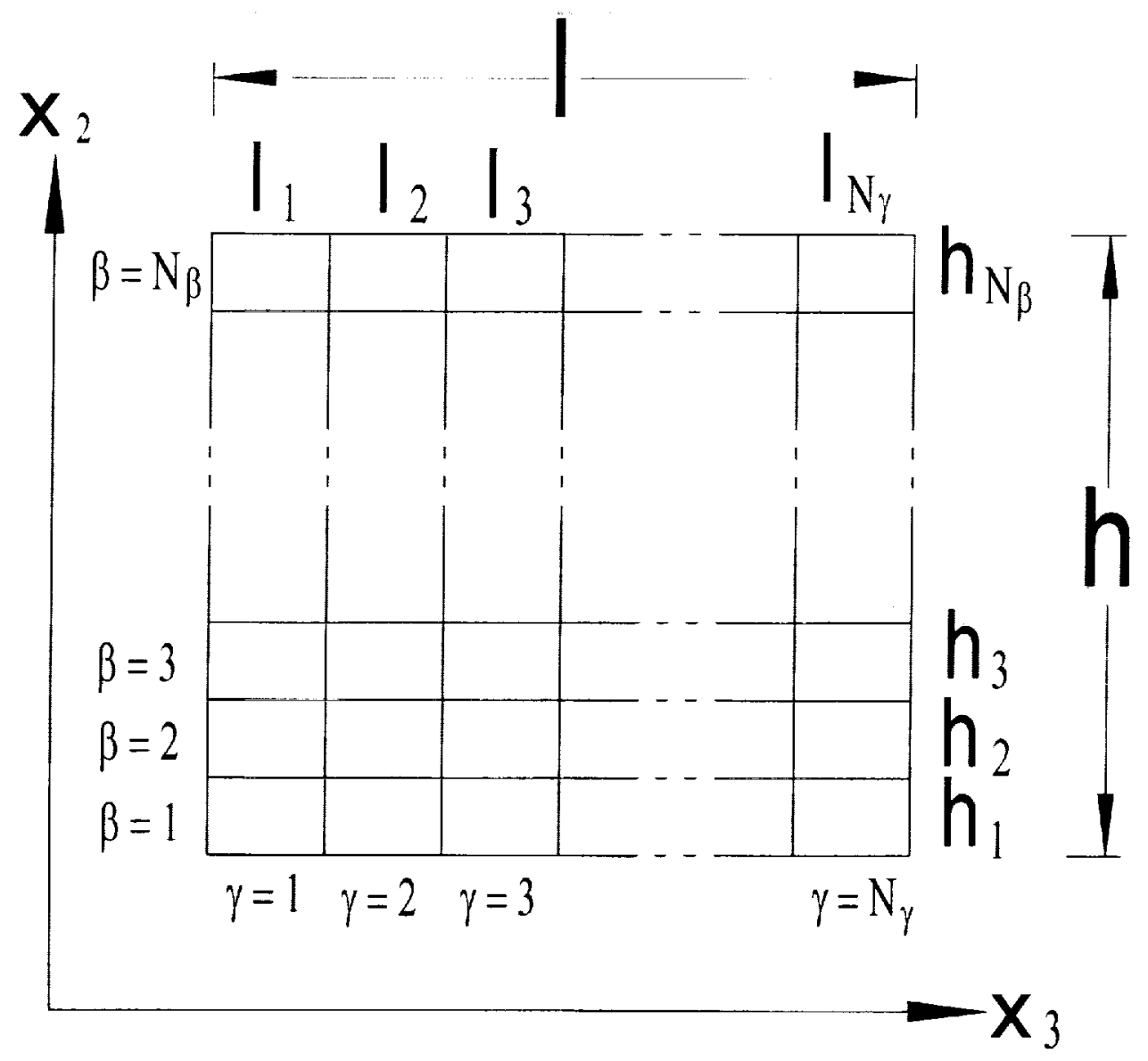

Figure 1. Doubly periodic GMC repeating unit cell. 


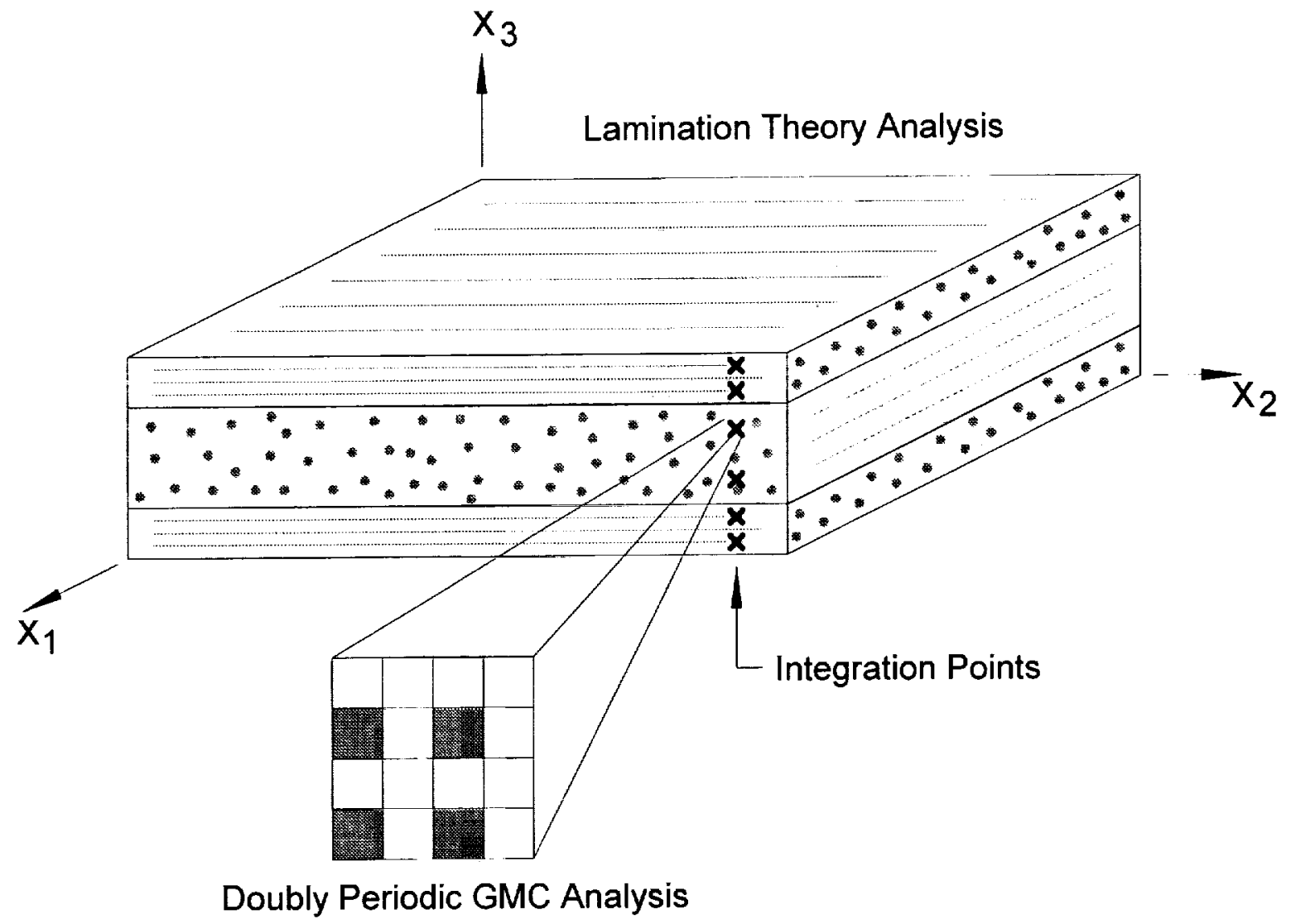

Figure 2. Schematic showing the lamination theory geometry with GMC embedded to represent the behavior of the composite material at the through-thickness integration points. 


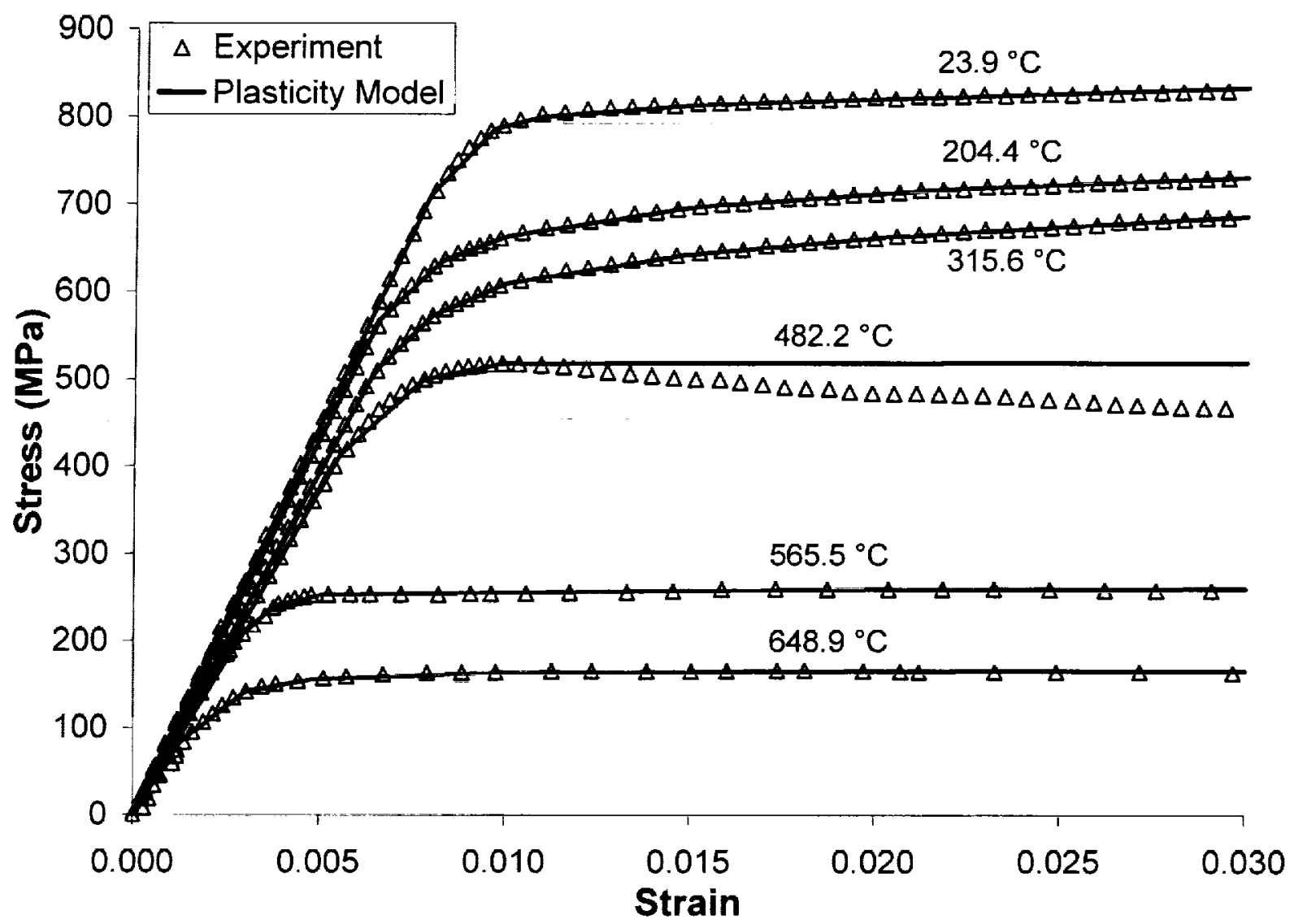

Figure 3. Characterization of the Mendelson incremental plasticity model for the Ti-15-3 matrix at various temperatures. These data represent an applied strain rate of $10^{-4} / \mathrm{s}$ (Tuttle and Rogacki, 1991). 


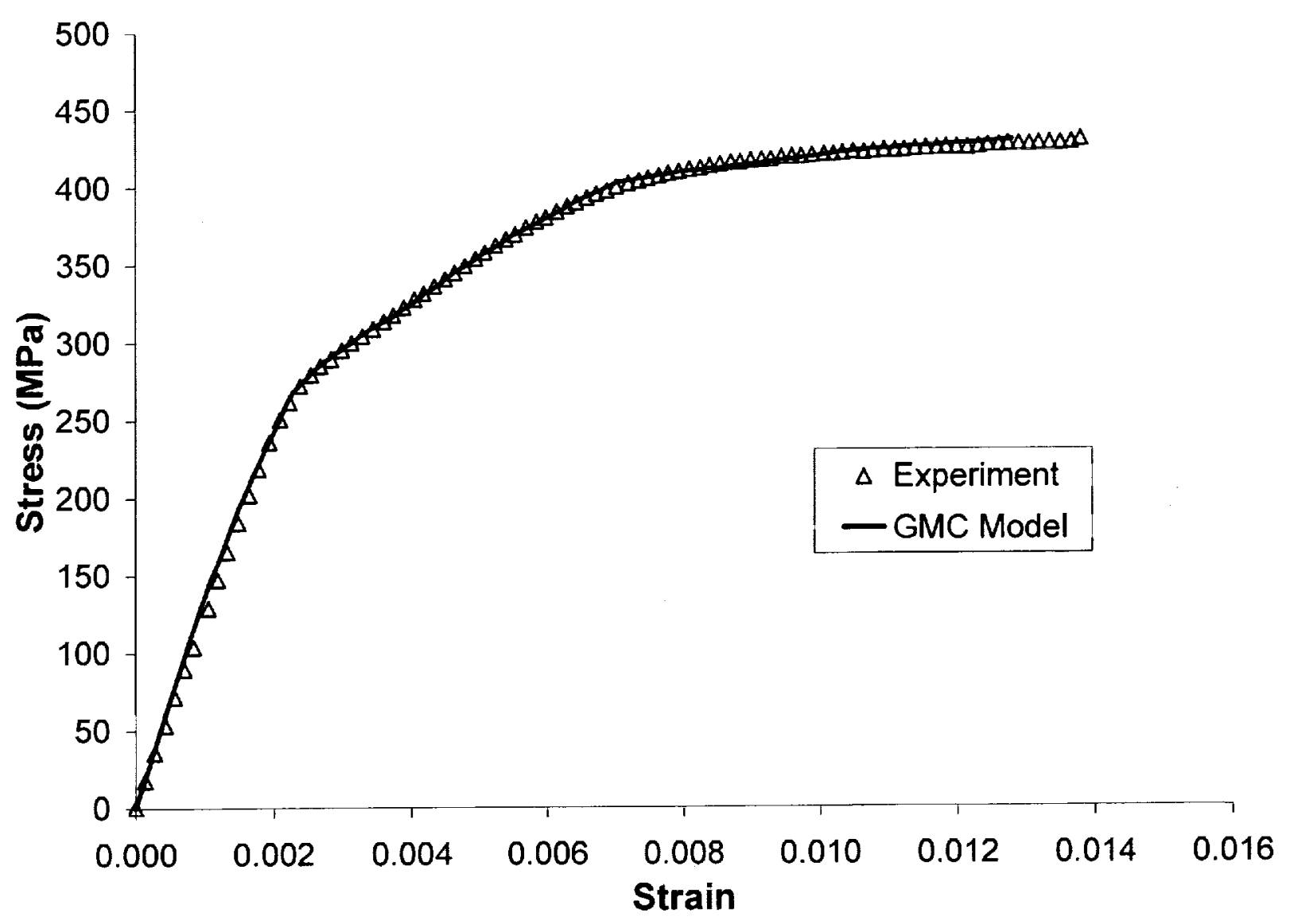

Figure 4. Transverse tensile response of 35\% SCS-6/Ti-15-3 at room temperature - characterization of the ECI model parameters. These data represent an applied strain rate of $10^{-4} / \mathrm{s}$. The curves' end points indicate failure. 


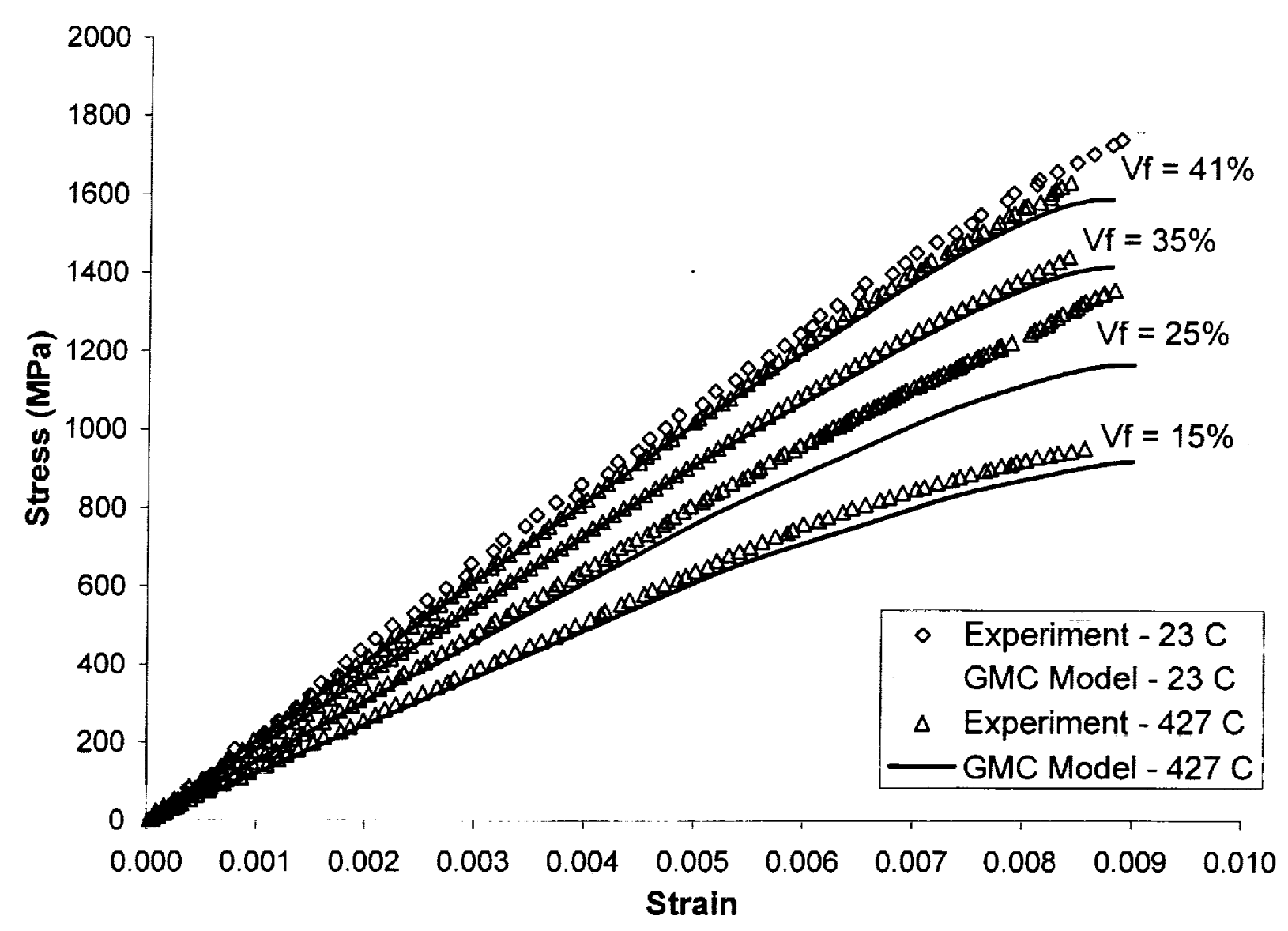

Figure 5. Comparison of GMC model results (employing the Curtin fiber breakage model) with experiment for the longitudinal tensile response of SCS-6/Ti-15-3. The $23{ }^{\circ} \mathrm{C}(\mathrm{Vf}=41 \%)$ results were employed to select the composite's stress-free temperature of $600{ }^{\circ} \mathrm{C}$. The curves' end points indicate failure. 


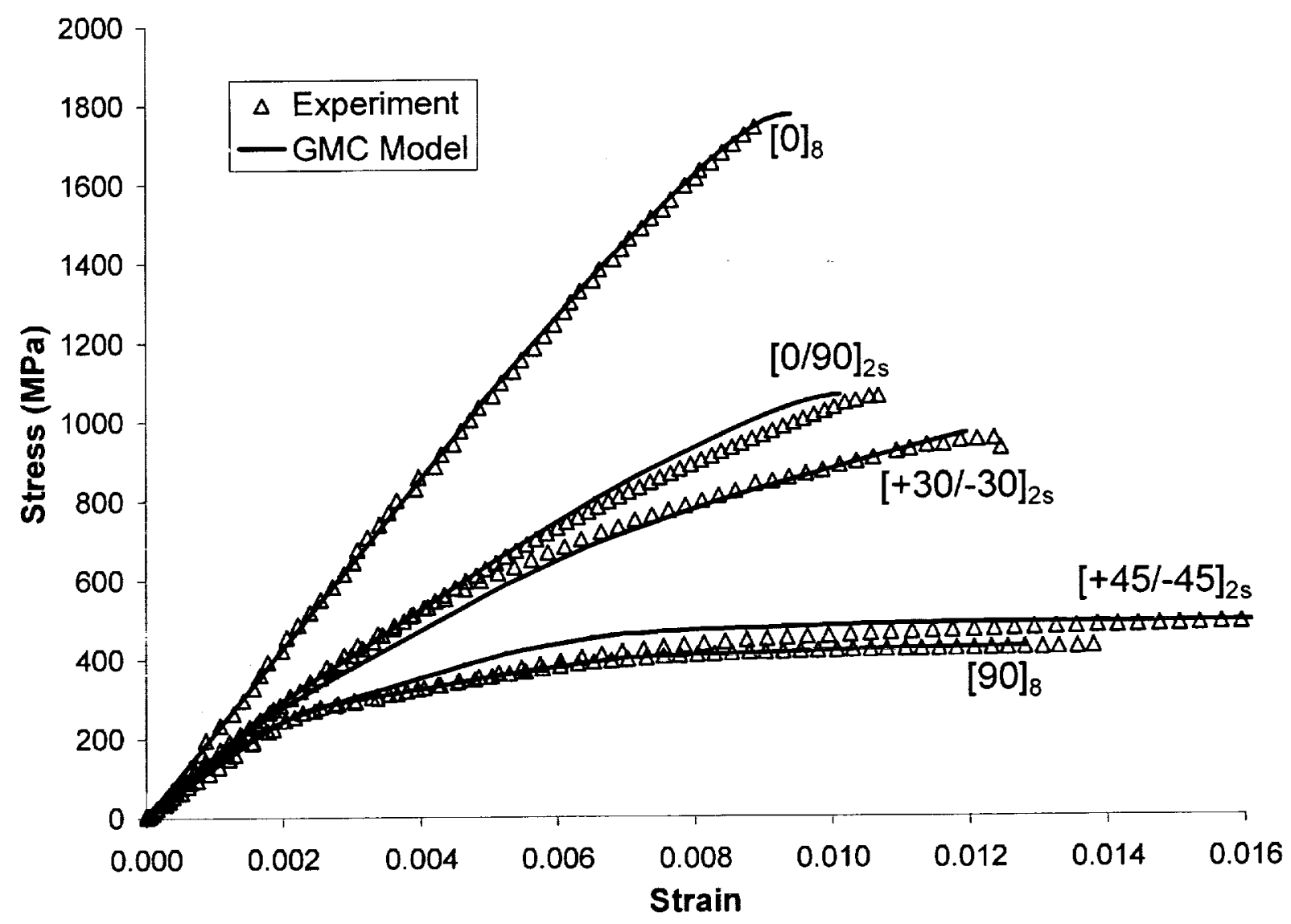

Figure 6. Comparison of GMC model results and experiment for the tensile response of SCS-6/Ti-15-3 laminates at $23{ }^{\circ} \mathrm{C}$. The fiber volume fraction for the $[0]_{8}$ composite was $41 \%$, for all others it was $35 \%$. The deformation of the $[0 / 90]_{2 s}$ and $[ \pm 30]_{2 \mathrm{~s}}$ laminates are pure predictions while the remaining model results included some correlation. The curves' end points represent failure in all cases except the $[ \pm 45]_{2 \mathrm{~s}}$ laminate, which experienced a run-out. 


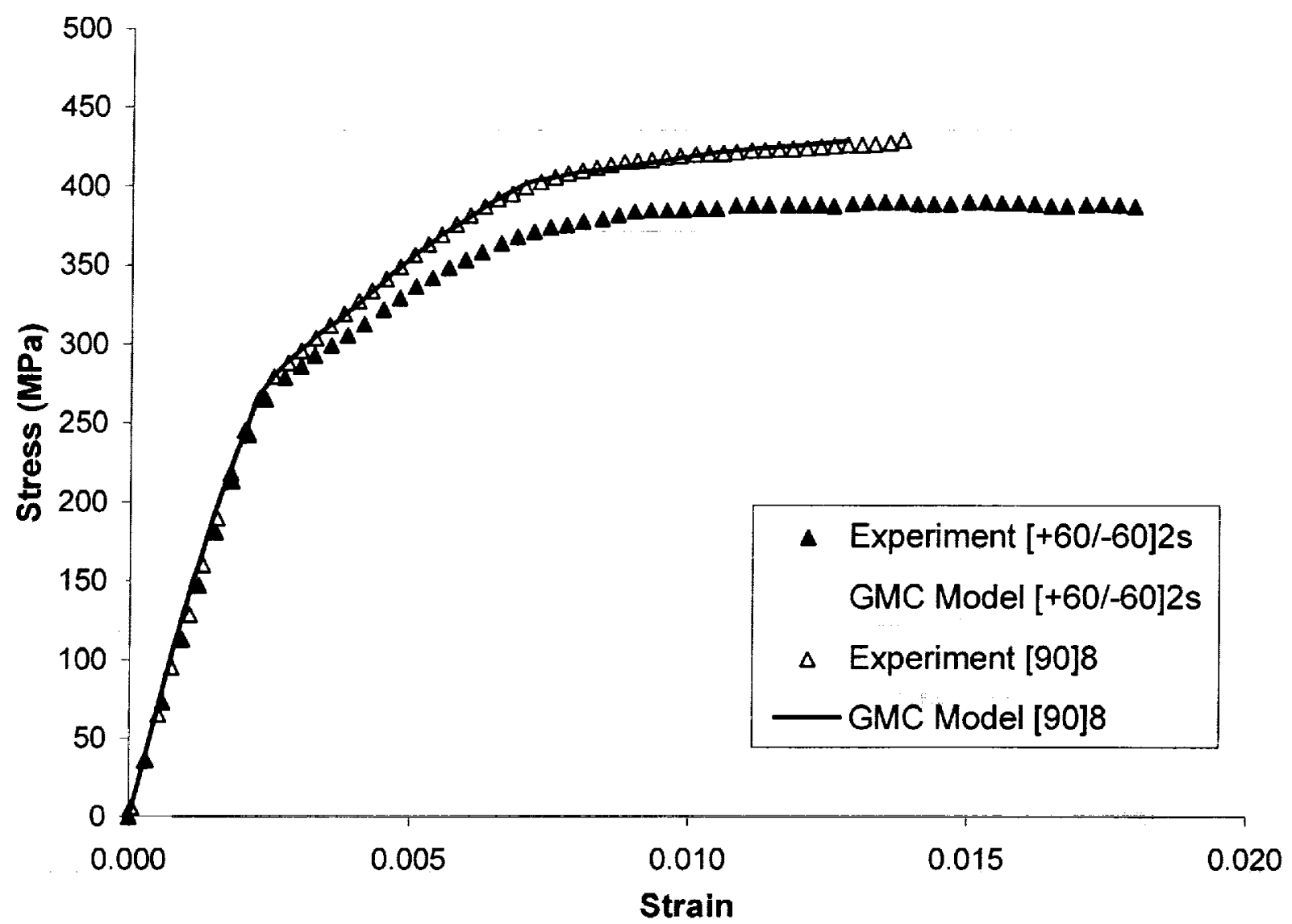

Figure 7. Comparison of GMC model results and experiment for the tensile response of $35 \% \mathrm{SCS}-6 / \mathrm{Ti}$ 15-3 laminates at $23{ }^{\circ} \mathrm{C}$. 


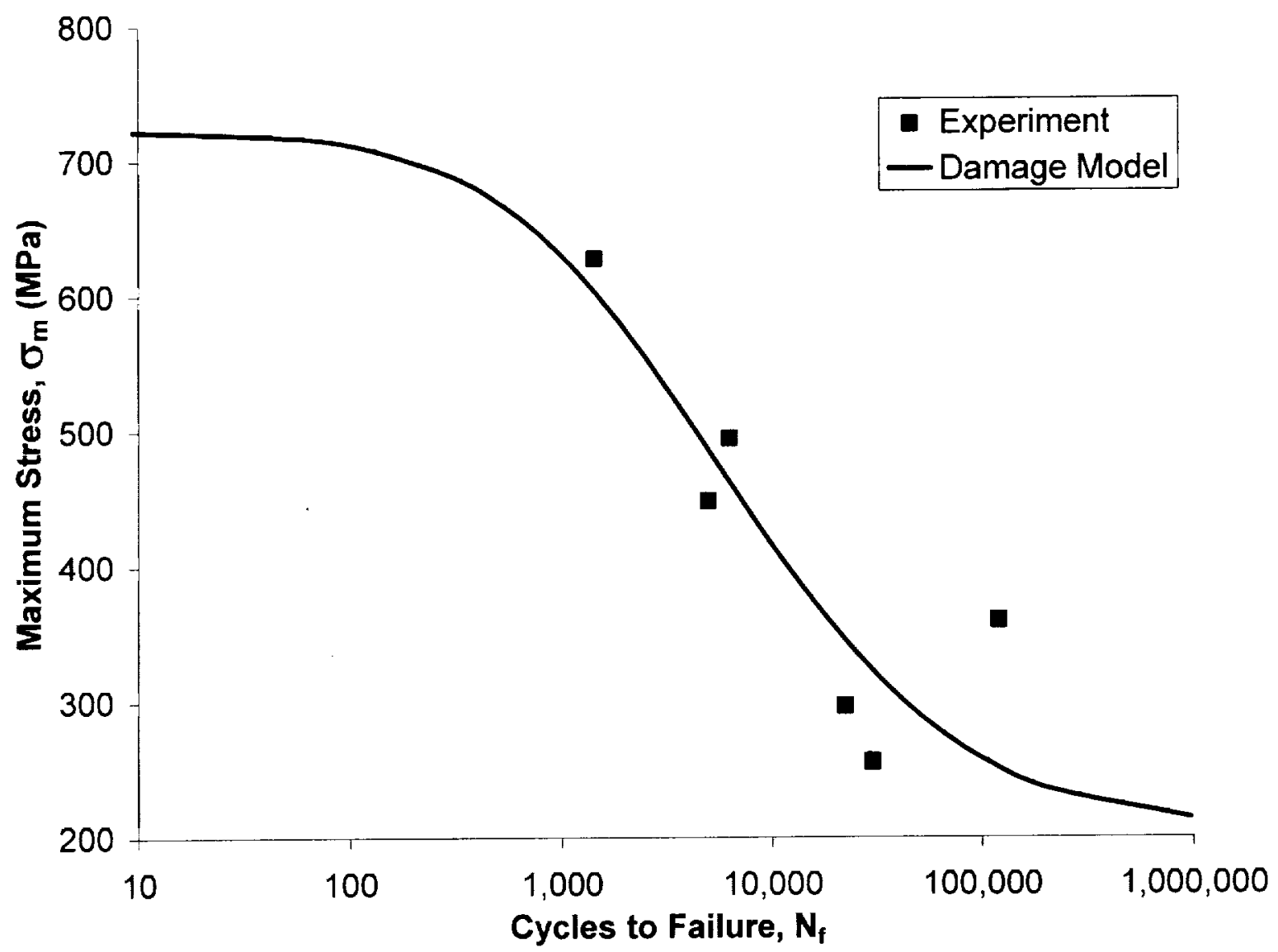

Figure 8. Correlation for the selection of damage model parameters for the Ti-15-3 matrix at $427^{\circ} \mathrm{C}$. These data represent fully reversed tests $(\bar{\sigma}=0, R=-1)$. 


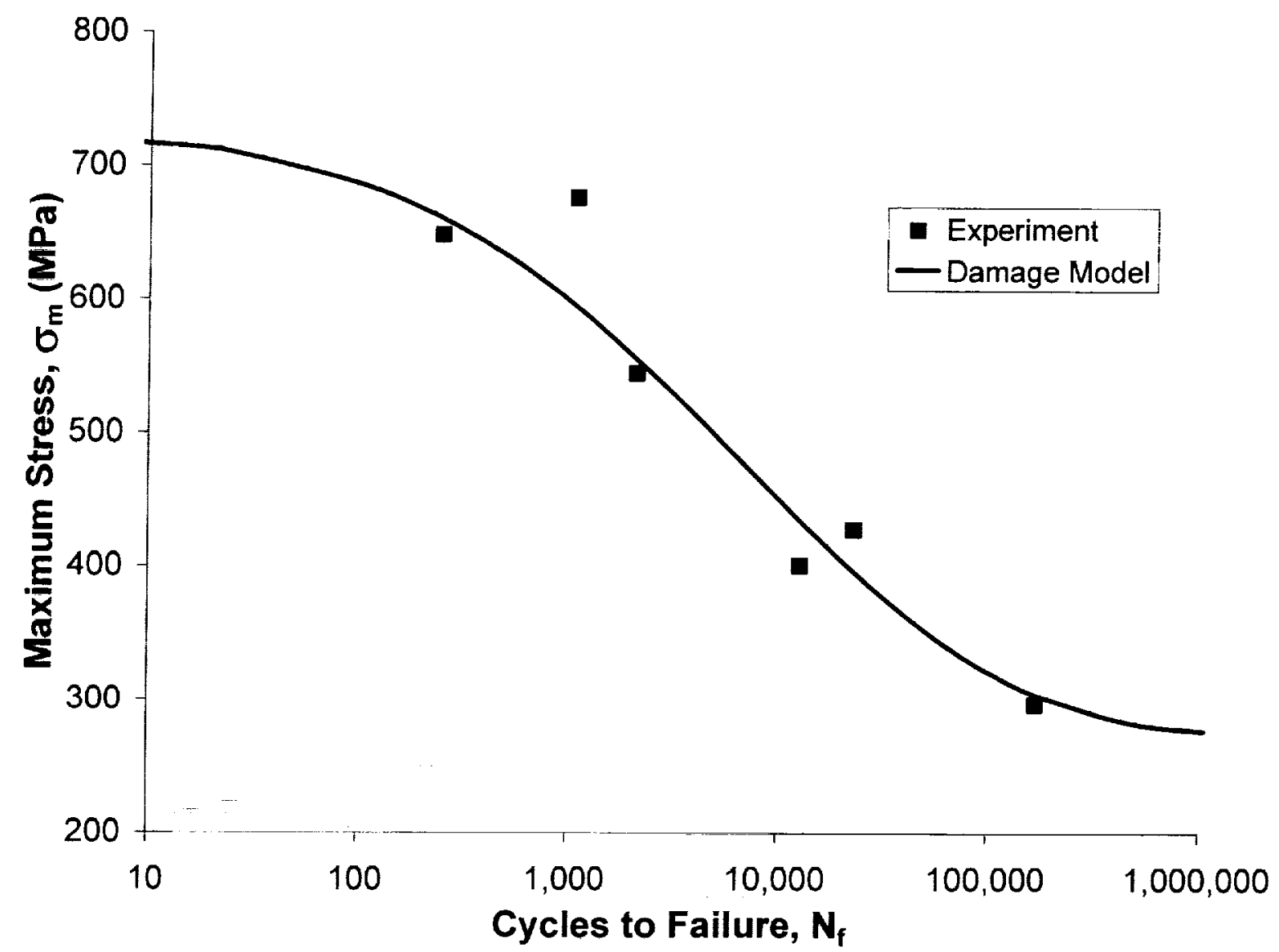

Figure 9. Correlation for the selection of damage model parameters for the Ti-15-3 matrix at $427{ }^{\circ} \mathrm{C}$. These data represent applied tensile stress states $(\bar{\sigma} \neq 0, R=0)$. 


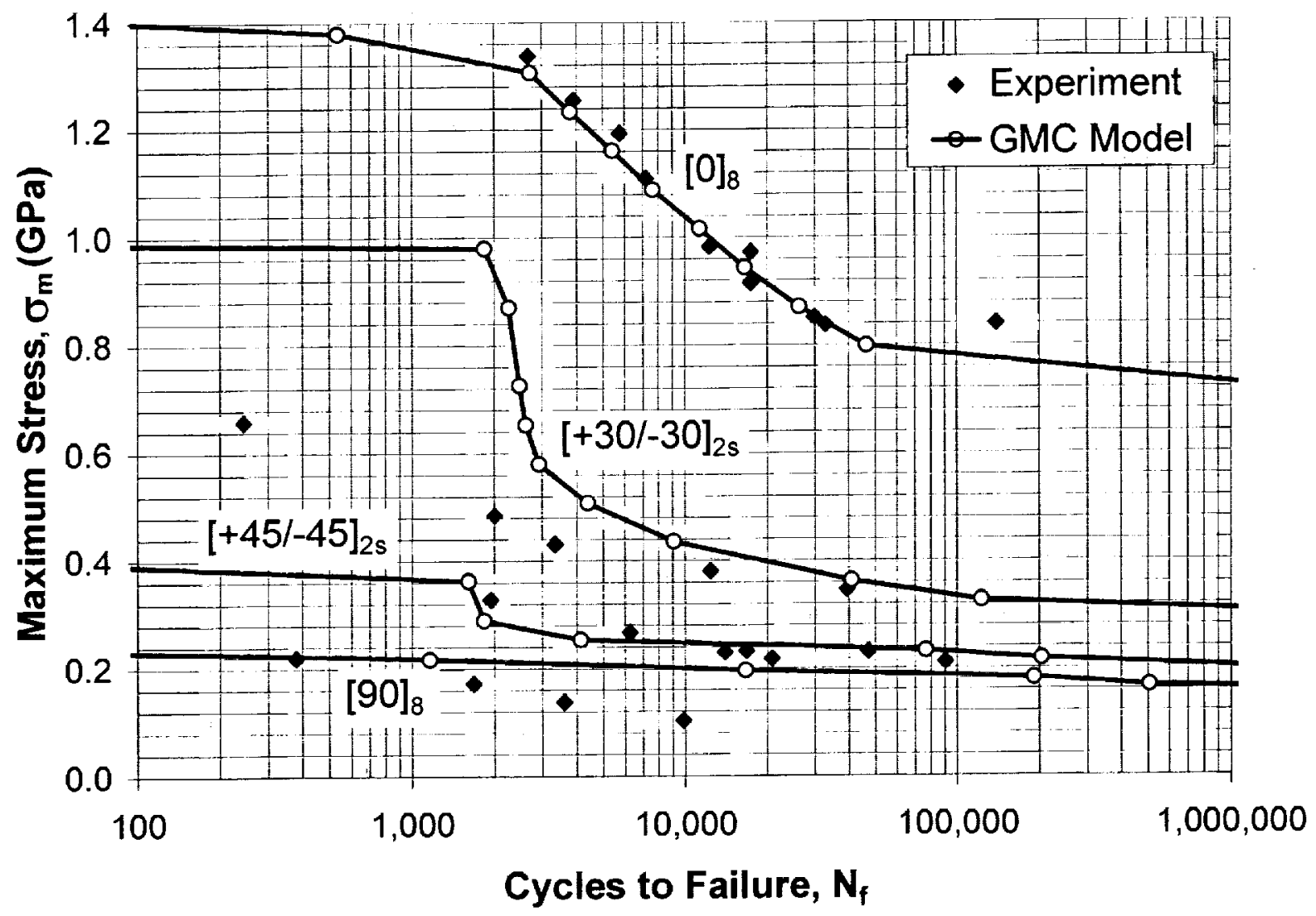

Figure 10. Comparison of model LCF life predictions (S-N curves) with experiment for 35\% SCS-6/Ti$15-3$ at $427{ }^{\circ} \mathrm{C}$. These data represent an $R$ ratio of 0.05 . Note that the [0] $]_{8}$ experimental results were used to correlate the fiber damage model below $1.04 \mathrm{GPa}$. 
Public reporting burden for this collection of informatlon is estimated to average 1 hour per response, including the time for reviewing instructions, searching existing data sources, gathering and maintaining the data needed, and completing and reviewing the collection of information. Send comments regarding this burden estimate or any other aspect of this Davis Highway, Suite 1204, Arlington, VA 22202-4302, and to the Office of Management and Budget, Paperwork Feduction Project (0704-0188), Washington, DC 20503.
Darson

1. AGENCY USE ONLY (Leave blank)

2. REPORT DATE
December $200 \mathrm{I}$

3. REPORT TYPE AND DATES COVERED

4. TITLE AND SUBTITLE

December 200

Fully Coupled Micro/Macro Deformation, Damage, and Failure Prediction for

SiC/Ti-15-3 Laminates

6. AUTHOR(S)

Brett A. Bednarcyk, Steven M. Arnold, and Brad A. Lerch

7. PERFORMING ORGANIZATION NAME(S) AND ADDRESS(ES)

National Aeronautics and Space Administration

John H. Glenn Research Center at Lewis Field

Cleveland, Ohio 44135-3191

Technical Memorandum

5. FUNDING NUMBERS

WU-708-72-42-00

9. SPONSORING/MONITORING AGENCY NAME(S) AND ADDRESS(ES)

National Aeronautics and Space Administration

Washington, DC 20546-0001
NASA TM-2001-211343

8. PERFORMING ORGANIZATION REPORT NUMBER

E-13160

10. SPONSORING/MONITORING AGENCY REPORT NUMBER

\section{SUPPLEMENTARY NOTES}

Brett A. Bednarcyk, Ohio Aerospace Institute, 22800 Cedar Point Road, Brook Park, Ohio 44142; Steven M. Arnold and Brad A. Lerch, NASA Glenn Research Center. Responsible person, Steven M. Arnold, organization code 5920 , 216-433-3334.

12a. DISTRIBUTION/AVAILABILITY STATEMENT

Unclassified - Unlimited

Subject Categories: 24 and 39

Available electronically at htp://glus.grc.nasa.gov/GLTRS

This publication is available from the NASA Center for AeroSpace Information, 301-621-0390.

13. ABSTRACT (Maximum 200 words)

The deformation, failure, and low cycle fatigue life of SCS-6/Ti-15-3 composites are predicted using a coupled deformation and damage approach in the context of the analytical generalized method of cells (GMC) micromechanics model. The local effects of inelastic deformation, fiber breakage, fiber-matrix interfacial debonding, and fatigue damage are included as sub-models that operate on the micro scale for the individual composite phases. For the laminate analysis, lamination theory is employed as the global or structural scale model, while GMC is embedded to operate on the meso scale to simulate the behavior of the composite material within each laminate layer. While the analysis approach is quite complex and multifaceted, it is shown, through comparison with experimental data, to be quite accurate and realistic while remaining extremely efficient.

\section{SUBJECT TERMS}

Metal matrix composites; Fatigue; Deformation; Plasticity; Failure; Micromechanics

17. SECURITY CLASSIFICATION OF REPORT

Unclassified

18. SECURITY CLASSIFICATION
OF THIS PAGE
Unclassified

Unclassified
19. SECURITY CLASSIFICATION OF ABSTRACT

Unclassified 